Purdue University

Purdue e-Pubs

2009

\title{
Analysis and Prediction of the Thermal Performance of Piezoelectrically Actuated Fans
}

T. Acikalin

Purdue University - Main Campus

S V. Garimella

Purdue University, sureshg@purdue.edu

Follow this and additional works at: http://docs.lib.purdue.edu/coolingpubs

Acikalin, T. and Garimella, S V., "Analysis and Prediction of the Thermal Performance of Piezoelectrically Actuated Fans" (2009). CTRC Research Publications. Paper 124.

http://dx.doi.org/10.1080/01457630802529115

This document has been made available through Purdue e-Pubs, a service of the Purdue University Libraries. Please contact epubs@purdue.edu for additional information. 


\title{
Analysis and prediction of the thermal performance of piezoelectrically actuated fans
}

\author{
TOLGA AÇIKALIN AND SURESH V. GARIMELLA
}

School of Mechanical Engineering, Purdue University, West Lafayette, USA

An experimentally validated numerical model is developed to analyze the operation of a piezoelectrically actuated cantilever vibrating close to a heated surface. The vibrating cantilever acts as a fan and provides localized cooling. The numerical results for the flow field and heat transfer show satisfactory agreement with experiments. The numerical model is used to develop fan curves for the piezoelectric fans, using a methodology similar to that used in constructing pump or fan curves for conventional fans. A simplified model based on stagnation region heat transfer in impingement flows is also proposed to estimate the heat transfer from a piezoelectric fan. The velocities obtained from the piezoelectric fan curves generated are used in this impingement heat transfer model, and the predictions are found to agree with measured stagnation zone Nusselt numbers with an average deviation of $17 \%$.

Address correspondence to Dr. Suresh V. Garimella, School of Mechanical Engineering, 585 Purdue Mall, Purdue University, West Lafayette, Indiana 47907-2088, USA. Tel: (765) 494-5621, Fax: (765) 494-0539, E-mail: sureshg@ purdue.edu 


\section{INTRODUCTION}

A piezoelectrically actuated vibrating cantilever induces fluid flow by converting electrical energy to mechanical vibrations, which in turn agitate the surrounding fluid. Such a vibrating cantilever is referred to as a fan in this work, since it provides localized cooling when the flow generated impinges on a heated surface, such as a heat sink mounted on a microelectronic device or a light emitting diode (LED) package. It is fabricated by bonding a piezoelectric patch (or several patches) to a shim material; alternatively, the patch itself can be used as the fan with no shim attached. Under an alternating voltage applied to the electrodes of the piezoelectric patch, the patch expands and contracts alternately at the same frequency as the input signal. The fan is driven at resonance, leading to a large tip deflection with small power consumption. To ensure silent operation, the fans are designed such that their operational mode of resonance (for the intensity of sound generated) is outside the range of frequencies audible to the human ear, i.e., less than $100 \mathrm{~Hz}$ for $25 \mathrm{~dB}$. Moreover, these fans consume very little power and can be fabricated to suit different geometrical constraints. These features of piezoelectric fans render them an attractive option for the thermal management of electronic devices.

A number of studies on piezoelectric fans have been reported in the literature. Toda [1,2] found that placing a piezoelectric fan on either side of a power transistor panel of a television receiver resulted in a $17^{\circ} \mathrm{C}$ decrease in temperature on the panel surface. Schmidt [3] employed the naphthalene sublimation technique to determine the local and average transfer coefficients on a vertical surface cooled by two piezoelectric fans resonating out of phase. Changing the distance between the fans and the surface, or the distance between fans, was found to noticeably change the transfer coefficients for the 
system. Yoo et al. [4] developed several types of piezoelectric fans and characterized the induced flow.

Flows around the ends of oscillating flexible cantilevers were investigated by Ihara and Watanabe [5]. The behavior for in-phase and out-of-phase vibration of cantilevers was studied. In the experiments, these cantilevers were sandwiched between two parallel plates to approximate a two-dimensional flow field. The experimental flow field was compared against numerical predictions obtained using vortex methods. Açıkalın et al. [6] developed a closed-form analytical solution to predict the twodimensional streaming flow from an infinite vibrating beam. This solution was used to develop a flow model for a baffled piezoelectric fan vibrating at its first mode of resonance in an infinite medium. Experimentally mapped flow patterns were found to closely match those predicted by the model for the baffled fan. Loh et al. [7] investigated the cooling effects of acoustic streaming from an ultrasonically vibrating beam. A $40^{\circ} \mathrm{C}$ temperature drop was observed on a heater which was initially at $98^{\circ} \mathrm{C}$. The beam vibrated at $28 \mathrm{kHz}$ with an amplitude of $25 \mu \mathrm{m}$. Kim et al. [8] investigated the flow field created by a vibrating plate using phase-resolved particle image velocimetry. They found that the flow field was two-dimensional near the cantilever tip, but became more complex and three-dimensional further downstream. Parameters of the vortices induced by the vibration of the cantilever were also estimated using the theory of oscillating deformable airfoils and compared against experiments.

Optimization of the structure of piezoelectric fans was investigated by Buermann et al. [9] and Basak et al. [10] who considered fans with two symmetrically placed piezoelectric patches and a piezoelectric patch on only one side, respectively. 
The feasibility of using piezoelectric fans in small-scale electronics cooling applications was investigated by Açıkalın et al. [11] and Wait et al. [12]. Flow visualization experiments were conducted to gain insight into the flow induced by these fans. The thermal performance of piezoelectric fans was investigated in a commercially available laptop computer. Temperature drops ranging from $6^{\circ} \mathrm{C}$ to $8^{\circ} \mathrm{C}$ were observed on the electronic components targeted within the laptop. In a more recent study, Açikalın et al. [13] considered a piezoelectric fan vibrating near a heat source to determine the effects of the fan amplitude, the distance between the fan and heat source, the fan length, its frequency offset from resonance, and the fan offset from the center of the heat source. A simplified numerical simulation of the flow field generated by some of the fans was also conducted and the results compared against the experiments.

Kimber et al. [14] investigated a piezoelectric fan vibrating near an electrically heated stainless steel foil. The temperature field was measured by an infrared camera, and two-dimensional contours of the local heat transfer coefficient were presented for different vibration amplitudes and gaps. Moreover, correlations were developed with appropriate Reynolds and Nusselt number definitions that describe the area-average thermal performance of the piezoelectric fan with an error of less than $12 \%$.

The fluid flow, and as a consequence the heat transfer, induced by a piezoelectric fan is quite complicated and depends on many factors as recognized in the literature. The aim of the present work is to develop and validate a numerical model for the operation of a piezoelectric fan. To assess the validity of the model, numerical predictions of the flow field are compared against particle image velocimetry (PIV) measurements. Predicted heat transfer distributions are compared against heat transfer experiments conducted 
using the experimental setup described in [14]. Given the complexity and computerintensive nature of the model, simplifications to the problem are explored and reducedorder models proposed. As part of the effort to provide simplified modeling tools for designers, fan curves for the piezoelectric fans are developed so that they can be incorporated into a design toolkit in a manner analogous to conventional fans. Finally, heat transfer coefficients induced by a piezoelectric fan are estimated by analogy with Falkner-Skan flows.

\section{DESCRIPTION OF THE PHYSICAL AND COMPUTATIONAL MODELS}

The experimental setups used in the flow field and heat transfer experiments are illustrated in Fig. 1. The flow visualization and PIV experiments are conducted in a liquid with a steel piezoelectric fan to facilitate particle seeding and imaging. The dielectric liquid used also allows for submersion of the whole setup including the piezoelectric fan. The heat transfer experiments are performed in air, consistent with the primary application for piezoelectric fans, which is in air cooling. The physical properties of air and HFE-7300 are summarized in Table 1.

In the flow field experiments, a $44 \mathrm{~mm}$ long steel fan (Piezo Systems, RFN1-LV02) is sandwiched between two transparent acrylic plates $(190 \mathrm{~mm} \times 98 \mathrm{~mm} \times 18 \mathrm{~mm})$ as illustrated in Fig. 1a. The fan is clamped to a copper block and positioned such that the fan is situated at the center of the setup. The assembly is immersed in a rectangular Pyrex container $(240 \mathrm{~mm} \times 195 \mathrm{~mm} \times 75 \mathrm{~mm})$ filled with the dielectric liquid, HFE7300.

The heat transfer experiments are carried out in air using the experimental setup developed in [14]. The setup is comprised of a thin stainless steel foil stretched between 
electrical busbars which provides a constant heat flux surface; a $65 \mathrm{~mm}$ long Mylar piezoelectric fan (Piezo Systems, RFN1-005) is used in these experiments as shown in Fig. 1b. The surface temperature on the back side of the foil is recorded by an infrared camera (ThermaCAM Merlin). A local flux balance is used to determine the convection coefficient due to the flow induced by the piezoelectric fan. Full details of the experimental setup and procedures are available in [14] and are not repeated here.

In the computational model, the three-dimensional geometry of the experimental setups is simplified to a two-dimensional domain. Laminar, incompressible flow is assumed with no radiation contributions; the two-dimensional nature of the model precludes buoyancy-induced convection from being considered. A schematic diagram of the numerical model, used for both the flow field and heat transfer computations, is shown in Fig. 2. The right boundary of the domain is set as a no-slip wall boundary condition. The top and bottom boundaries are set as zero-pressure outlets, while the left boundary is set as a zero-pressure inlet. In the heat transfer model, in addition to these boundary conditions the right boundary is subjected to a uniform heat flux.

Although the piezoelectric fans were actuated by one (Mylar fan) or two (stainless steel fan) attached piezoceramic patches, the geometry of the fan is reduced to that of a simple beam in the numerical model, and the presence of the piezoelectric patches is neglected. The actual geometry of the fan, however, is not critical in the numerical model since the motion of the fan is used as an input and not calculated. In any case, the patched portion of a piezoelectric fan undergoes very little displacement compared to the unpatched portion during fan vibration, and can be neglected in the interest of simplifying the mesh. The instantaneous location of the vibrating beam was an input to the model as 
a no-slip displacement boundary condition. A seventh-order least squares polynomial fit $\left(\mathrm{R}^{2}>0.999\right)$ is used to represent the mode shape given in [13] for the Mylar piezoelectric fan vibrating in air:

$$
\begin{aligned}
& f(x)=-42.3402 x^{2}+33587.5 x^{3}-2.7317 \times 10^{6} x^{4} \\
& +9.05342 \times 10^{7} x^{5}-1.2653 \times 10^{9} x^{6}+6.34496 \times 10^{9} x^{7}
\end{aligned}
$$

In Equation (1), $\mathrm{x}$ is the $\mathrm{x}$-coordinate of the fan in meters $(\mathrm{x}=0$ corresponds to the clamped end of the fan and $\mathrm{x}=0.065 \mathrm{~m}$ corresponds to the tip of the fan). The mode shape was scaled to achieve the desired amplitude and then multiplied by $\sin (2 \pi \cdot f r \cdot t)$ to describe the location of the piezoelectric fan in time. The vibration amplitude of the steel piezoelectric fan in HFE-7300, on the other hand, is very small. At the suggested maximum voltage of $42 \mathrm{~V}$, the amplitude of the fan is $1.5 \mathrm{~mm}$ (peak-to-peak). Highspeed imaging of the fan vibration revealed that the portion of the steel fan bearing the piezoelectric patch barely vibrates at the fan amplitudes considered: when the fan amplitude is $1.5 \mathrm{~mm}$ (peak-to-peak), the patch domain vibrates by less than $0.1 \mathrm{~mm}$. Thus, for the stainless steel fan, the vibration of the free (unpatched) portion of the fan is described simply as a rotating beam, hinged at the end of the piezoelectric patch portion of the fan.

The resonance frequency of the Mylar fan is $60 \mathrm{~Hz}$ in air. To achieve numerical stability, a value of $62.5 \mathrm{~Hz}$ is used instead since this value for the resonance frequency corresponds to a period of $0.016 \mathrm{~s}$, enabling a time step that can be expressed as a rational number. The use of a rational number as the time step ensured that, during each period of vibration, the fan experiences exactly the same extreme locations, i.e., the peak-to-peak fan amplitude is identical in every cycle. The resonance frequency of the steel fan in HFE-7300 is approximately $31.25 \mathrm{~Hz}$, which is a value that is conducive for the choice of 
computational time steps. The time step in the numerical model is chosen to allow 40 time steps per vibration cycle.

\section{FLOW FIELD MEASUREMENT AND PREDICTION}

\section{Flow Field Experiments}

To best match the two-dimensional numerical model, a very wide fan would be desired for the experiment, so that its mid-plane would be largely two-dimensional in behavior, with minimal edge effects. However, such a fan was not commercially

available. An additional complication is introduced by the presence of a free surface in the liquid immersion tank used for visualization. The vibrating fan was found to cause significant surface waves, resulting in unacceptable levels of optical distortion in the imaging. To account for these two constraints, the flow visualization and PIV experiments were conducted with a fan of finite width, sandwiched between two side walls. In order to make the experimental flow field as two-dimensional as possible, the distance between the sides of the fan and the containing walls was minimized to $0.15 \mathrm{~mm}$ on each side. Two different values, $1 \mathrm{~mm}$ and $2.5 \mathrm{~mm}$, are considered for the tip-toimpingement wall gap.

A light sheet generated from a diode-pumped $\mathrm{Nd}: \mathrm{YVO}_{4}$ laser using a cylindrical aspheric lens with a hyperbolic profile illuminates the mid-plane of the experimental setup. A high-speed camera (Photron Ultima-APX) captures top-view images of the flow field. Flour particles are used as tracers to visualize the flow patterns.

The PIV analysis is conducted on a set of 2000 frames obtained at a speed of 500 frames per second using the high-speed camera. The size of each image captured by the 
camera is 1024 by 1024 pixels. Each image is divided into a grid of 16 pixels by 16 pixels for PIV analysis using custom-developed software. A cross-correlation algorithm is used to calculate the velocity of the flow from these images, as described in Jones et al. [15]. The parameters used in the PIV analysis of the experimental flow field are summarized in Table 2. The analysis is conducted only on one half of the domain on an area of approximately $60 \mathrm{~mm}$ by $60 \mathrm{~mm}$. The investigation of only one side of the experimental domain allows a more detailed PIV analysis. Additionally, the presence of the clamp holding the piezoelectric fan (Fig. 1) affects the flow field on the other side, and is not accounted for in the numerical model.

\section{Flow Field Model}

The commercially available computational fluid dynamics software package CFD-ACE [16] is used to perform the numerical simulations. A first-order upwind discretization scheme is used for the momentum equations. For the discretization in time, a first-order Euler scheme is used. A structured mesh is preferred for ease of implementation of the deforming mesh modules. At every time step, the new location of the fan is calculated and the domain remeshed. A transfinite interpolation scheme is used to calculate the new locations of the nodes at every time step. An advanced multigrid solver is then used to calculate the velocity, pressure and enthalpy. The pressure-velocity coupling is accomplished via the SIMPLEC algorithm. Normalized convergence criteria for all of the numerical computations in this work are set to $10^{-8}$ for the u-, v-, and wvelocities as well as enthalpy. 
The numbers of nodes used in the numerical model for predicting the flow field induced by the steel fan in HFE-7300 are 13,800 and 14,500 for the gaps of $1 \mathrm{~mm}$ and 2.5 $\mathrm{mm}$, respectively. The predicted velocities at the fan exit vary by less than $0.002 \mathrm{~m} / \mathrm{s}$ when the number of nodes for each case is increased by $40 \%$.

It may be noted that, for both the flow and temperature fields in this inherently transient problem, the values reported in this work are cycle-averaged values, calculated after such a time at which a periodic steady state is reached.

\section{Comparison of Visualized and Predicted Flow Patterns}

Experimental visualizations of the steel fan vibrating at an amplitude of $1.5 \mathrm{~mm}$ (peak-peak) at two different gaps are presented in Fig. 3a. These "streakline" images are obtained by superposition of individual photographs captured by the high-speed camera. As seen from these images, the flow field for the gaps of $1 \mathrm{~mm}$ and $2.5 \mathrm{~mm}$ are very similar.

Streamlines obtained from the PIV analysis are shown in Fig. 3b, while the predicted flow fields for these cases from the numerical model are illustrated in Fig. 3c. In the panels in this figure, the piezoelectric fan is located on the horizontal line passing $y$ $=0 \mathrm{~m}$, and the tip of the fan is located at $\mathrm{x}=0.044 \mathrm{~m}$. For both gaps, the shapes of the streamlines are very similar for the regions close to the fan but not near the fan tip. Both the PIV measurements and the predictions show that the streamline through $\mathrm{x}=0 \mathrm{~m}, \mathrm{y}=$ $-0.015 \mathrm{~m}$ separates the flow into two regions. Fluid above this line approaches the fan, while fluid below this line enters the domain from the left and is ejected from the bottom. 
Flow field measurements are not extended further beyond this demonstration of general qualitative agreement between measured and predicted flow fields. Due to the very localized and highly transient flow patterns near the impingement wall and close to the fan tip, the PIV analysis has limited accuracy in estimating the velocities in these regions. Moreover, it is possible that the tracer particles do not exactly follow the flow as they tend to deposit on the acrylic walls or agglomerate over time; the presence of the top and bottom walls in the experimental setup (not present in the 2D numerical model) also alter the flow, especially farther away from the piezoelectric fan. It may be noted that these sources of error bias the PIV results to be lower than would be obtained in an ideal two-dimensional geometry.

Since the primary objective of this work is to estimate the heat transfer induced by a piezoelectric fan for the thermal management of electronic components, and in view of the difficulties associated with making accurate velocity measurements in the complex, transient flow field involved, further validation of the numerical model was conducted against results from heat transfer experiments as described in the following.

\section{HEAT TRANSFER MEASUREMENT AND PREDICTION}

\section{Heat Transfer Model}

The numerical model used to predict the heat transfer induced by a piezoelectric fan was discussed earlier and shown in Fig. 2. The right wall of the domain is subjected to a uniform heat flux of $650 \mathrm{~W} / \mathrm{m}^{2}$, has a thickness of $50 \mu \mathrm{m}$ and a thermal conductivity of $20 \mathrm{~W} / \mathrm{mK}$. The value of heat flux, thickness and thermal conductivity on this wall are set to match the experiments [14]. In the event of backflow existing through the zero- 
pressure gradient boundaries, the temperature of the backflow is set to $300 \mathrm{~K}$, matching the ambient air temperature in the experiments. The properties of air used in the model are included in Table 1. To achieve more accurate results in the heat transfer model, a second-order discretization is used for both the momentum and energy equations.

The amplitude of the fan took values of $6.35,7.5,8.5$, and $12 \mathrm{~mm}$ in the numerical simulations to match the experimental settings. The gap between the fan tip and the wall is varied through $0.5,1,2.5$ and $10 \mathrm{~mm}$. While some of these experiments were available in [14], additional heat transfer experiments are conducted to complete the experimental matrix for the present work using the experimental setup and procedures described in [14]. The estimated uncertainty in the experimental heat transfer coefficients is $\pm 8 \%$.

Since the domain size is different for each gap, four different meshes are used during these numerical simulations. The mesh-independence of the results is established based on the temperature profile calculated on the uniform heat flux surface for each of the four meshes. The results are judged to be mesh-independent when the change in temperature was less than $0.1{ }^{\circ} \mathrm{C}$ for at least a $50 \%$ increase in the number of grids. Table 3 summarizes the details of the meshes used. Also, an increase in the number of time steps per cycle of fan vibration from 40 to 100 resulted in a difference in temperature of less than $0.05^{\circ} \mathrm{C}$ for an amplitude (denoted by A) of $10 \mathrm{~mm}$ and a gap (denoted by G) of $2.5 \mathrm{~mm}$.

While most of the simulations considered a two-dimensional representation of the piezoelectric fan domain as discussed thus far, a three-dimensional model was investigated for one representative case with $\mathrm{A}=10 \mathrm{~mm}$ and $\mathrm{G}=1 \mathrm{~mm}$ to assess the 
validity of the assumption of two-dimensionality. The three-dimensional model is again constructed to match the experimental setup. Only the top half of the domain is modeled, and the bottom surface of the domain is set as a symmetry boundary condition. This boundary condition sets the velocity vector gradient as well as the temperature gradient to zero across this boundary. The top surface of the three-dimensional model is also set as a zero pressure gradient outlet, matching the experimental setup. All other boundary conditions in this model are identical to the two-dimensional models. Hence only the top half of the full domain is modeled, where the height of the fan (in the z-direction) is 6.35 $\mathrm{mm}$, and the total height of the numerical domain is $50 \mathrm{~mm}$. A mesh-independent twodimensional mesh is extruded 32 times in the $\mathrm{z}$-direction to generate the mesh for the three-dimensional model. The resulting three-dimensional mesh had approximately 450,000 nodes. Only one three-dimensional case is investigated in this work due to its highly intensive computational demands. The case considered took more than 6 weeks to run on a dual-processor, $3 \mathrm{GHz}$ workstation.

\section{Results for a Representative Case $(A=10 \mathrm{~mm}, G=1 \mathrm{~mm})$}

Velocity contours and streamlines for the cycle-averaged developed flow from the two-dimensional model for this case are shown in Fig. 4. Unlike the results presented in Açıkalın et al. [13], no distinct circulation zones are observed, except the two small vortices near the tip of the piezoelectric fan. This different behavior is due to the difference in boundary conditions simulated in the numerical models. The model investigated in [13] did not have inlet or outlet boundary conditions and the flow induced by the piezoelectric fan was confined in an enclosure. In the current model, on the other 
hand, the flow is not confined and is free to enter or exit the numerical domain via the inlet and outlet boundaries. The maximum cycle-averaged velocity for this case is $5 \mathrm{~m} / \mathrm{s}$ and is observed very close to the tip of the fan. This compares to the maximum tip velocity of the fan beam itself of $3.93 \mathrm{~m} / \mathrm{s}$. But for a few localized spots, most of the flow has a velocity between 0.5 and $2 \mathrm{~m} / \mathrm{s}$ inside the domain. The cycle-averaged flow in this case strongly resembles an impingement (stagnation) flow, suggesting the possibility of applying correlations or analytical solutions developed for stagnation flows to piezoelectric fans.

Temperature and heat transfer coefficient profiles predicted by the two- and threedimensional models are compared in Fig. 5. The temperatures and heat transfer coefficients for both models agree to within $20 \%$ of each other. Since the temperature and heat transfer coefficient profiles do not change significantly in the z-direction, it may be inferred that the flow exiting the fan is indeed largely two-dimensional. Experimentally determined heat transfer coefficients also provide reasonable validation for the results predicted by the simplified 2D model, considering the experimental uncertainty. It is noted that due to the computationally intensive nature of the problem, only one 3D case is modeled with limited convergence tests. To obtain accurate 3D results, it is recommended that parallel computing be utilized and a full design of experiments by numerical modeling be conducted. 


\section{PARAMETRIC STUDY}

Having established that the two-dimensional model provides a reasonable and cost-effective representation of the piezofan heat transfer, numerical results from the twodimensional model are explored further in this section, in terms of comparisons with the experimental heat transfer results as well as the effect of the governing parameters. Predicted local Nusselt numbers along the heater are compared with the experimental values in Fig. 6 and Fig. 7. The location on the heater is non-dimensionalized by the amplitude. Fig. 6 shows the measured and predicted local Nusselt numbers on the impingement surface for $\mathrm{A}=7.5,8.5,10$, and $12 \mathrm{~mm}$ for a range of fan-to-heated surface gaps. In these and subsequent plots both experimental and numerical local Nusselt numbers are calculated as in a slot jet, with $N u=h \cdot D_{h} / k$, where $h$ is the local heat transfer coefficient, $D_{h}$ is the hydraulic diameter, and $k$ is the thermal conductivity of air. For the two-dimensional cases presented here, $D_{h}=2 \cdot A$, where $A$ is the amplitude of the piezoelectric fan. The numerical predictions agree reasonably with the experiments, and also show the optimum gap to be approximately $2.5 \mathrm{~mm}$, as observed in the experiments for all the amplitudes under consideration.

Fig. 7 shows the same comparison as a function of non-dimensional location on the heat source at $\mathrm{G}=0.5 \mathrm{~mm}, \mathrm{G}=1 \mathrm{~mm}, \mathrm{G}=2.5 \mathrm{~mm}$, and $\mathrm{G}=10 \mathrm{~mm}$, for a range of fan amplitudes. The two-dimensional numerical predictions capture the experimental trends to a reasonable degree. As expected, the local Nusselt number decreases as the amplitude decreases in both the experiments and the the numerical predictions.

Fig. 8 compares the measured and predicted values of the stagnation Nusselt numbers for all the gaps and amplitudes investigated. It is clear that the numerical model 
is able to successfully capture the effect of the fan to wall gap, predicting an optimum gap of about $2.5 \mathrm{~mm}$ for the maximum stagnation heat transfer. The general trend with amplitude is also captured reasonably well, with the stagnation Nusselt number decreasing for decreasing amplitude. It may be noted that for larger amplitudes, i.e., $\mathrm{A}=$ $12 \mathrm{~mm}$, the numerical model somewhat underpredicts the Nusselt numbers, whereas for the smallest amplitude of $6.35 \mathrm{~mm}$, the numerical model overpredicts the Nusselt number. However, the agreement between the predicted and measured results is reasonable, with a match to within $\pm 20 \%$, except for the case with the smallest amplitude and largest gap $(\mathrm{A}=6.35 \mathrm{~mm}$ and $\mathrm{G}=10 \mathrm{~mm})$. Since this case has the slowest flow, i.e., the weakest jet, as well as the largest distance to the heat source, the flow induced by the fan in this case is expected to be much more prone to three-dimensional effects. Kimber et al. [14] also reported that for a G/A ratio of 2 the heat transfer caused by the fan is not localized as it was at the smaller G/A ratios. In conjunction with the findings in [14], it is believed that beyond a G/A of 2, the flow can no longer be assumed two-dimensional.

\section{DEVELOPMENT OF PIEZOELECTRIC-FAN CURVES}

Fig. 9 shows the u-velocity and pressure profiles at the exit of the piezoelectric fan $(x=0.065 \mathrm{~m},-\mathrm{A}<\mathrm{y}<\mathrm{A})$. The u-velocity profile at the exit of the fan can be assumed constant within the fan envelope, $0<\mathrm{y} / \mathrm{A}<1$, based on these results. Also at this gap, the maximum $\mathrm{u}$-velocities are observed at the smallest amplitude $(\mathrm{A}=6.35$ $\mathrm{mm})$, whereas the maximum pressure is observed for the largest amplitude $(\mathrm{A}=12 \mathrm{~mm})$. Although the occurrence of a higher velocity at a smaller amplitude might be counterintuitive, this observation is reasonable as it pertains only to u-velocity. Indeed, Fig. 10 
shows that both the flow rate and the velocity magnitude at the exit of the fan decrease with decreasing amplitude. One other conclusion that can be drawn from Fig. 10 is that the y-component of the velocity is affected more by an increase in fan amplitude; Fig. 9 showed smaller changes in u-velocity with a change in amplitude. Similar trends were observed for the other gaps, $\mathrm{G}=0.5 \mathrm{~mm}, \mathrm{G}=2.5 \mathrm{~mm}$, and $\mathrm{G}=10 \mathrm{~mm}$ (data not shown). It may also be noted that the lack of smoothness in the u-velocity profile (in Fig. 9 and Fig. 10) arises from the need for a number of interpolations needed to calculate the cycleaveraged values. The mesh is different at each time step in a given cycle due to the motion of the piezoelectric fan. At every time step, the results are first interpolated to a fixed mesh with the fan vibration envelope excluded, after which the time averaging is performed.

The flow rate and pressure trends observed for different amplitudes and gaps suggest that fan curves can be constructed for the piezoelectric fans. In Fig. 11 calculated flow rates as well as average total pressure at the exit of the fan are plotted as square symbols for different gaps and amplitudes. The instantaneous total pressure is first calculated by CFD-ACE and the cycle-averaged total pressure is then averaged over the exit area of the fan.

The constant-gap and constant-amplitude lines are also plotted in Fig. 11, as dashed and solid lines, respectively. The constant-gap lines in this figure strongly resemble the system curves of traditional fans and the constant amplitude lines resemble the performance curves, and will be referred to as such in the following. The construction and scaling of the system curves is presented first followed by a discussion of the performance curves of piezoelectric fans. 
A quadratic curve, $P=C \cdot Q^{2}$, can be fitted to the available results to describe the system curves, with a correlation coefficient $R^{2}>0.99$. A least-squares fit for this equation at different gap values shows that the constant $C \propto 1 / \mathrm{G}^{2}$. Thus, the system of curves can be represented by

$$
P=C_{1} \cdot \frac{Q^{2}}{G^{2}}
$$

where $\mathrm{P}$ is total pressure $(\mathrm{Pa})$, and the constant takes a value of $C_{1}=0.535$.

In a similar fashion, the fan performance curves have the form, $P=P_{0}-C \cdot Q^{2}$. In this equation $\mathrm{P}$ is the total pressure, $\mathrm{P}_{0}$ is the shut-off pressure (zero-flow), and $\mathrm{C}$ is a constant. When the results are fitted to this equation, the shut-off pressure is seen to scale with amplitude $\mathrm{A}$, and the constant $\mathrm{C}$ scales as $1 / A^{2}$. Hence the following equation is suggested for the piezoelectric-fan performance curves,

$$
P=C_{2} \cdot A-C_{3} \frac{Q^{2}}{A^{2}}
$$

where $C_{2}=2260$, and $C_{3}=0.385$. Eliminating pressure from Equations (2) and (3) yields the following equation for the flow rate that depends only on the amplitude and gap:

$$
Q=\sqrt{\frac{C_{2} A}{\frac{C_{1}}{G^{2}}+\frac{C_{3}}{A^{2}}}}
$$

As can be seen from Fig. 11 the fan-curve model is able to accurately represent the numerical predictions. The average and maximum error in flow rate between the fan- 
curve model and numerical predictions are $2.63 \%$ and $5.43 \%$, respectively, while these values for pressure are $3.65 \%$ and $12.51 \%$, respectively.

An additional test case with $A=15 \mathrm{~mm}$ and $\mathrm{G}=5 \mathrm{~mm}$ was also simulated in the CFD model to verify the fan-curve model. The flow rate and pressure for this test case is also plotted as a circle symbol and compared against the fan-curve model (dotted-lines) in Fig. 11. The fan-curve model is able to predict this case very well, even though the parameters $\mathrm{A}$ and $\mathrm{G}$ for this case were beyond the ranges used in creating the fan-curve model. The difference in the flow rate is $6.16 \%$, while that in the total pressure is less than $0.01 \%$.

It should be noted that the fan curves are expected to depend on the fan geometry, as well as the fan's operating resonance frequency. Moreover, enclosure confinement issues are expected to play a role on fan curve characteristics and these issues are explored in other work in the authors' group [17].

\section{Prediction of thermal performance based on the fan curves}

As was noted earlier, the cycle-averaged flow induced by the piezoelectric fan strongly resembles an impingement or stagnation flow (Falkner-Skan flows with wedge angle $=180^{\circ}$ ). The treatment of such flows and the associated heat transfer is available in many textbooks (e.g., [18]). In the stagnation region, the heat transfer coefficient is constant since the velocity boundary layer thickness is constant in this region. The velocity boundary layer and the heat transfer coefficient for stagnation flow on a constant-temperature surface can be expressed as [18] 


$$
\begin{aligned}
& \delta=2.4 \cdot\left(\frac{v}{C}\right)^{1 / 2} \\
& h=0.5 \cdot k \cdot\left(\frac{C}{v}\right)^{1 / 2}
\end{aligned}
$$

for a Prandtl number of 0.71. In Equation (5), the constant $C$ is the magnitude of the velocity gradient. Values of $\mathrm{C}$ can be found from potential-flow solutions based on the average fan exit velocity. From potential flow theory, it can be shown that $C=U_{\infty} / G$. Further, $U_{\infty}$ can be estimated for different amplitudes and gaps from the fan-curve model (Equation 4) as $Q /(2 \cdot A)$, since the stagnation area extends over a dimension that is twice the fan amplitude.

The stagnation Nusselt numbers predicted by the model and their deviation from the experimental values are tabulated in Table 4. The stagnation Nusselt number can be estimated to within an average deviation of $17 \%$ of the experimental values by first obtaining the flow rate from the fan-curve model (Equation 4) and then using the simplified stagnation flow analysis described above (Equation 5). This approach therefore provides a reasonable first-order estimation of piezoelectric fan performance, without necessitating a full CFD solution of the rather complex and transient flow and thermal fields induced by these fans.

Although for the smallest gap of $0.5 \mathrm{~mm}$ the agreement between this approach and the experiments is satisfactory, this approach is not recommended for gap values smaller than the boundary layer thickness on the impingement surface. As discussed earlier, the constant $\mathrm{C}$ in Equation (5) is obtained from potential flow theory which is valid only outside the boundary layer. Therefore it may be applied only for cases where the gap is larger than the boundary layer thickness. The velocity boundary layer 
thickness in this problem varies between $0.45 \mathrm{~mm}$ to $0.53 \mathrm{~mm}$ depending on the amplitude.

\section{CONCLUSIONS}

The fluid flow, and as a consequence the heat transfer, induced by a piezoelectric fan is quite complicated and depends on many factors as recognized in the literature. In this work an experimentally validated numerical model is developed to characterize such a fan. To assess the validity of the model, numerical predictions of the flow field are compared against experimental PIV measurements; predicted heat transfer distributions are compared against the heat transfer experiments conducted on the experimental setup described in [14]. The numerical model agreed to within $\pm 20 \%$ of the heat transfer experiments, except for the case with the smallest amplitude and largest gap.

Given the complexity and computer-intensive nature of the numerical model, simplifications to the problem are explored and reduced-order models are proposed based on the results of the numerical model. As part of this effort to provide simplified modeling tools for designers, fan curves for the piezoelectric fans are developed. Finally, heat transfer coefficients induced by a piezoelectric fan are estimated by analogy with Falkner-Skan flows based on the fan curves. These estimations were able to approximate the experimental stagnation Nusselt numbers with an average deviation of $17 \%$.

The present study investigated two parameters, the amplitude of the fan and the gap between the fan and heat source. In addition to these parameters, it is known that the length of the fan as well as the frequency of the fan can alter its heat transfer 
characteristics. The proposed models can further be extended to include these additional parameters. 


\section{Nomenclature}

A Fan amplitude [mm] (2A is the peak-to-peak amplitude)

C Constant relating pressure to flow rate

$\mathrm{D}_{\mathrm{h}} \quad$ Hydraulic diameter $[\mathrm{m}]$

fr $\quad$ Fan resonance frequency $[\mathrm{Hz}]$

G Gap between the fan tip and wall or heat source [mm]

h Local heat transfer coefficient $\left[\mathrm{W} / \mathrm{m}^{2} \mathrm{~K}\right]$

$\mathrm{k} \quad$ Thermal conductivity $[\mathrm{W} / \mathrm{mK}]$

$\mathrm{Nu} \quad$ Local Nusselt number, $\mathrm{Nu}=2 \mathrm{hA} / \mathrm{k}$

$\mathrm{Nu}_{0} \quad$ Stagnation point Nusselt number

$\mathrm{Nu}_{\mathrm{s}} \quad$ Stagnation region Nusselt number

P Total Pressure [Pa]

$\mathrm{P}_{0} \quad$ Shut-off pressure $[\mathrm{Pa}]$

Pr Prandtl number, $\operatorname{Pr}=v / \alpha$

Q Flow rate per unit fan width $\left[\mathrm{m}^{2} / \mathrm{s}\right]$

$\mathrm{R}^{2} \quad$ Coefficient of determination

$\mathrm{t} \quad$ Time $[\mathrm{s}]$

$\mathrm{u} \quad \mathrm{X}$-component of velocity $[\mathrm{m} / \mathrm{s}]$

$U_{\infty} \quad$ X-component of velocity far from the surface $[\mathrm{m} / \mathrm{s}]$

$\mathrm{v} \quad \mathrm{y}$-component of velocity $[\mathrm{m} / \mathrm{s}]$

W $\quad$ z-component of velocity $[\mathrm{m} / \mathrm{s}]$

$\mathrm{x} \quad \mathrm{x}$-coordinate $[\mathrm{m}]$

y $\quad y$-coordinate $[\mathrm{m}]$ 
$\mathrm{z} \quad \mathrm{z}$-coordiante $[\mathrm{m}]$

\section{Greek symbols}

$a \quad$ Thermal diffusivity $\left[\mathrm{m}^{2} / \mathrm{s}\right]$

$\delta \quad$ Boundary layer thickness [m]

$v \quad$ Kinematic viscosity $\left[\mathrm{m}^{2} / \mathrm{s}\right]$ 


\section{REFERENCES}

[1] Toda, M., Theory of air flow generation by a resonant type $\mathrm{PVF}_{2}$ bimorph cantilever vibrator, Ferroelectrics, Vol. 22, pp. 911-918, 1979.

[2] Toda, M., Voltage-induced large amplitude bending device- $\mathrm{PVF}_{2}$ bimorph-Its properties and applications, Ferroelectrics, Vol. 32, pp. 127-133, 1981.

[3] Schmidt, R. R., Local and average transfer coefficients on a vertical surface due to convection from a piezoelectric fan, Procs. ITHERM, pp. 41- 49, Washington, DC, 1994.

[4] Yoo, J. H., Hong J. I. and Cao W., Piezoelectric ceramic bimorph coupled to thin metal plate as cooling fan for electronic devices, Sensors and Actuators A, Vol. 79, pp. 8-12, 2000.

[5] Ihara, A. and Watanabe, H., On the flow around flexible plates, oscillating with large amplitude, Journal of Fluids and Structures, Vol. 8, pp. 601-619, 1994.

[6] Açıkalın, T., Raman, A. and Garimella, S.V., Two-dimensional streaming flows induced by resonating, thin beams, Journal of the Acoustical Society of America, Vol. 114, pp. 1785-1795, 2003.

[7] Loh, B. G., Hyun, S., Ro, P. I. and Kleinstreuer C., Acoustic streaming induced by ultrasonic flexural vibrations and associated enhancement of convective heat transfer, Journal of the Acoustical Society of America, Vol. 111, pp. 875-883, 2002. 
[8] Kim, Y.-H., Wereley, S.T. and Chun C.-H., Phase-resolved flow field produced by a vibrating cantilever plate between two endplates, Physics of Fluids, Vol. 16, pp. 145-162, 2004.

[9] Buermann, P., Raman, A. and Garimella, S.V., Dynamics and topology optimization of piezoelectric fans, IEEE Transactions on Components and Packaging Technologies, Vol. 25, pp. 113-121, 2002.

[10] Basak, S., Raman, A. and Garimella, S. V., Dynamic response optimization of piezoelectrically excited thin resonant beams, ASME Journal of Vibration and Acoustics, Vol. 127, pp. 18-27, 2005.

[11] Açıkalın, T., Wait, S. M., Garimella, S. V. and Raman A., Experimental investigation of the thermal performance of piezoelectric fans, Heat Transfer Engineering, Vol. 25, pp. 4-14, 2004.

[12] Wait, S. M., Basak, S., Garimella, S. V. and Raman A., Piezoelectric fans using higher flexural modes for electronics cooling applications, IEEE Transactions on Components and Packaging Technologies, Vol. 30, pp. 119-128, 2007.

[13] Açıkalın, T., Garimella, S. V, Raman A. and Petroski J., Characterization and Optimization of the Thermal Performance of Miniature Piezoelectric Fans, International Journal of Heat and Fluid Flow, Vol. 28, pp. 806-820, 2007. 
[14] Kimber, M., Garimella S. V. and Raman A., Local heat transfer coefficients induced by piezoelectrically actuated vibrating cantilevers, ASME Journal of Heat Transfer, Vol. 129, pp. 1168-1176, 2007.

[15] Jones, B. J., Lee P. -S. and Garimella S. V., Infrared micro-particle image velocimetry measurements and predictions of flow distribution in a microchannel heat sink, International Journal of Heat and Mass Transfer available online 31 August 2007.

[16] CFD-ACE+ V2006, ESI Group, Paris, France.

[17] Kimber, M. L., Suzuki, K., Kitsunai, N., Seki, K. and Garimella, S.V., Quantification of piezoelectric fan performance under actual implementation conditions, Procs. ITHERM, Lake Buena Vista, Florida, May 28-31, 2008.

[18] Burmeister L. C., Convective Heat Transfer, John-Wiley and Sons, New York, NY, 1993. 
Table 1. Physical properties of air and dielectric liquid.

\begin{tabular}{lc|c} 
& Air & HFE-7300 \\
\hline Density $\left[\mathrm{kg} / \mathrm{m}^{3}\right]$ & 1.1614 & 1660 \\
Viscosity $[\mathrm{kg} / \mathrm{m}-\mathrm{s}]$ & $1.85 \times 10^{-5}$ & $1.18 \times 10^{-3}$ \\
Specific heat $[\mathrm{J} / \mathrm{kg}-\mathrm{K}]$ & 1007 & --- \\
Thermal conductivity $[\mathrm{W} / \mathrm{m}-\mathrm{K}]$ & 0.0263 & ---
\end{tabular}


Table 2. Parameters used in the PIV analysis of the experimental flow field.

\begin{tabular}{ll} 
Number of images & 2000 \\
Camera speed & $500 \mathrm{fps}$ \\
Image size & $1024 \times 1024$ pixels \\
Grid size & $16 \times 16$ pixels \\
Interrogation window & $32 \times 32$ pixels \\
Search radius & 13 pixels \\
\hline
\end{tabular}


Table 3. Meshes used in the heat transfer model.

\begin{tabular}{lc} 
Mesh & Number of nodes \\
\hline$G=0.5 \mathrm{~mm}$ & 12030 \\
$\mathrm{G}=1 \mathrm{~mm}$ & 11544 \\
$\mathrm{G}=2.5 \mathrm{~mm}$ & 11878 \\
$\mathrm{G}=10 \mathrm{~mm}$ & 16242
\end{tabular}


Table 4. Stagnation region Nusselt number compared against experiments.

\begin{tabular}{|c|c|c|c|c|c|c|}
\hline & \multicolumn{2}{|c|}{$A=12 \mathrm{~mm}$} & \multicolumn{2}{|c|}{$A=10 \mathrm{~mm}$} & \multicolumn{2}{|c|}{$A=8.5 \mathrm{~mm}$} \\
\hline & $\mathrm{Nu}_{\mathrm{s}}$ & $\%$ Error & $\mathrm{Nu}_{\mathrm{s}}$ & $\%$ Error & $\mathrm{Nu}_{\mathrm{s}}$ & $\%$ Error \\
\hline $\mathrm{G}=10 \mathrm{~mm}$ & 46.8 & $-29.0 \%$ & 39.4 & $-25.7 \%$ & 33.6 & $-20.0 \%$ \\
\hline $\mathrm{G}=2.5 \mathrm{~mm}$ & 51.4 & $-28.8 \%$ & 44.7 & $-23.8 \%$ & 39.4 & $-21.0 \%$ \\
\hline $\mathrm{G}=1 \mathrm{~mm}$ & 51.7 & $-24.1 \%$ & 45.1 & $-20.5 \%$ & 39.9 & $-18.0 \%$ \\
\hline \multirow[t]{7}{*}{$\mathrm{G}=0.5 \mathrm{~mm}$} & 51.8 & $-23.0 \%$ & 45.1 & $-20.0 \%$ & 40.0 & $-15.9 \%$ \\
\hline & & \multicolumn{2}{|c|}{$\mathrm{A}=7.5 \mathrm{~mm}$} & \multicolumn{2}{|c|}{$\mathrm{A}=6.35 \mathrm{~mm}$} & \\
\hline & & $\mathrm{Nu}_{\mathrm{s}}$ & $\%$ Error & $\mathrm{Nu}_{\mathrm{s}}$ & $\%$ Error & \\
\hline & $\mathrm{G}=10 \mathrm{~mm}$ & 29.6 & $-15.0 \%$ & 24.9 & $18.8 \%$ & \\
\hline & $\mathrm{G}=2.5 \mathrm{~mm}$ & 35.7 & $-11.2 \%$ & 31.3 & $3.6 \%$ & \\
\hline & $\mathrm{G}=1 \mathrm{~mm}$ & 36.3 & $-1.6 \%$ & 32.0 & $11.2 \%$ & \\
\hline & $\mathrm{G}=0.5 \mathrm{~mm}$ & 36.4 & $-0.5 \%$ & 32.1 & $16.8 \%$ & \\
\hline
\end{tabular}




\section{LIST OF FIGURE CAPTIONS}

Fig. 1 Rendering of the experimental setup used in the (a) flow visualization and PIV experiments, and (b) heat transfer experiments.

Fig. 2 Schematic diagram of the numerical model used in the flow field analysis.

Fig. 3 Velocity field induced by the steel piezoelectric fan vibrating at $1.5 \mathrm{~mm}$ (peakpeak) amplitude in HFE-7300 with a gap of $1 \mathrm{~mm}$ (left column), and $2.5 \mathrm{~mm}$ (right column). (a) Streaklines constructed from superposition of successive images, (b) streamlines obtained using PIV, and (c) those predicted from the numerical model, respectively are shown in each column.

Fig. 4 Cycle-averaged (a) velocities, and (b) streamlines for $A=10 \mathrm{~mm}$ and $\mathrm{G}=1 \mathrm{~mm}$. Fig. 5 Comparison of (a) temperature, and (b) heat transfer coefficient for the 3D model at different heights against the 2D model results. The experimental heat transfer coefficients for this amplitude of $10 \mathrm{~mm}$ and gap of $1 \mathrm{~mm}$ are also plotted.

Fig. 6 Comparison of measured (M) and predicted (P) local Nusselt numbers for different gaps at amplitudes of (a) $7.5 \mathrm{~mm}$, (b) $8.5 \mathrm{~mm}$, (c) $10 \mathrm{~mm}$, and (d) $12 \mathrm{~mm}$. Fig. 7 Comparison of measured (M) and predicted (P) local Nusselt numbers for different amplitudes at gaps of (a) $0.5 \mathrm{~mm}$, (b) $1 \mathrm{~mm}$, (c) $2.5 \mathrm{~mm}$, and (d) $10 \mathrm{~mm}$. Fig. 8 Comparison of measured (M) and predicted (P) stagnation point Nusselt numbers. Fig. 9 u-velocity (left y-axis) and pressure (right y-axis) profiles as a function of nondimensional y (y/A) plotted for various amplitudes at $\mathrm{G}=1 \mathrm{~mm}$.

Fig. 10 Velocity magnitude profile for non-dimensional y (y/A) plotted for various amplitudes at $\mathrm{G}=1 \mathrm{~mm}$.

Fig. 11 Development of fan curves for the piezoelectric fan. 


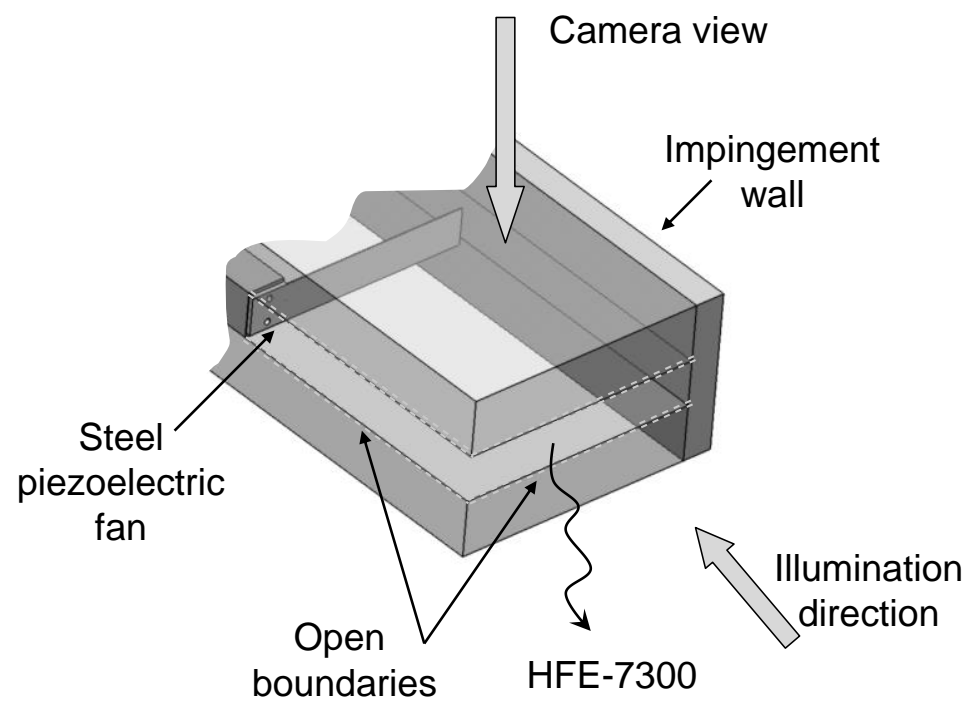

(a)

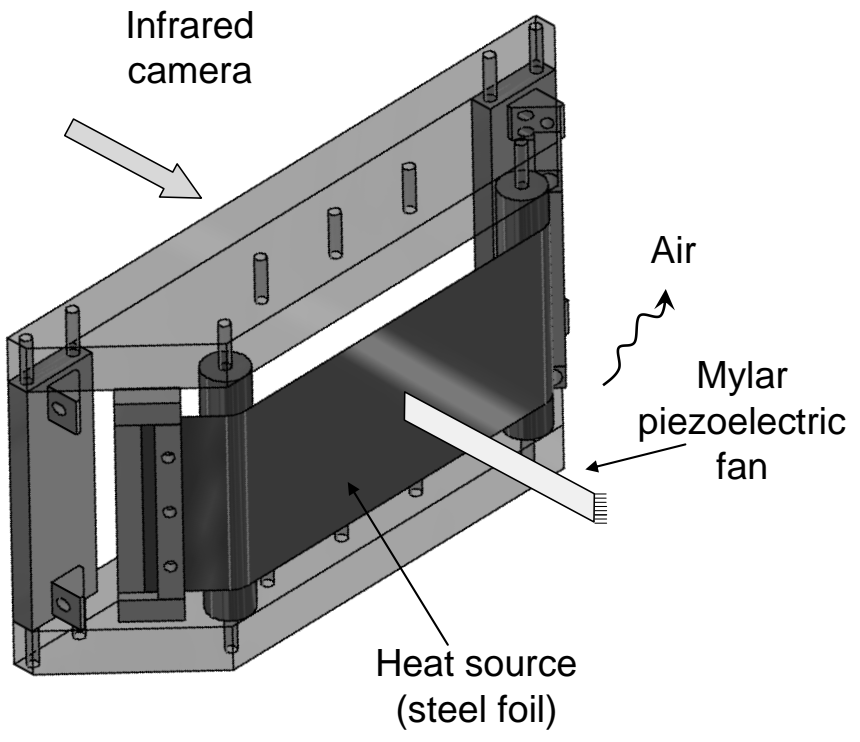

(b)

Fig. 1 Rendering of the experimental setup used in the (a) flow visualization and PIV experiments, and (b) heat transfer experiments. 


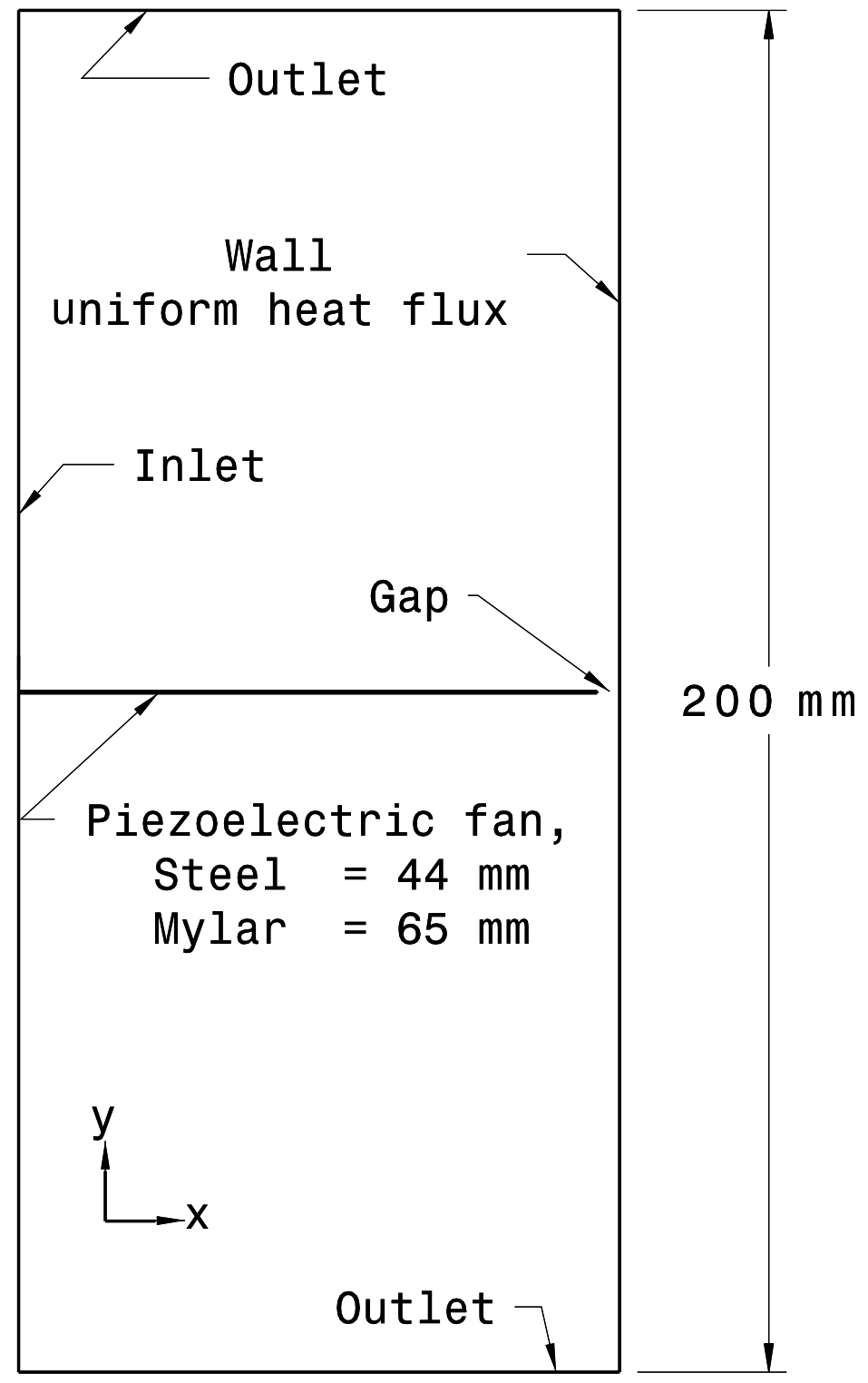

Fig. 2 Schematic diagram of the numerical model used in the flow field analysis. 

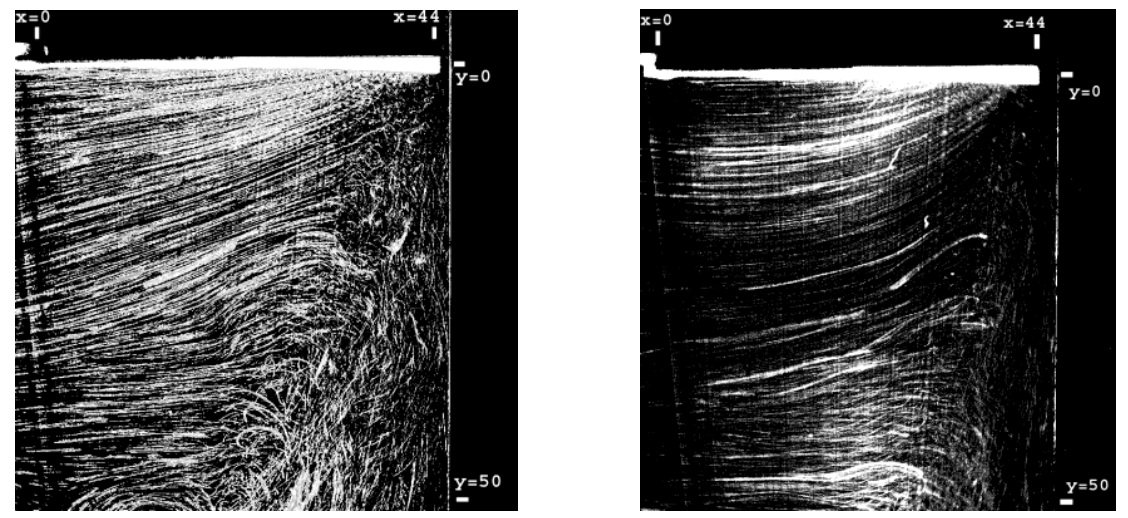

(a)
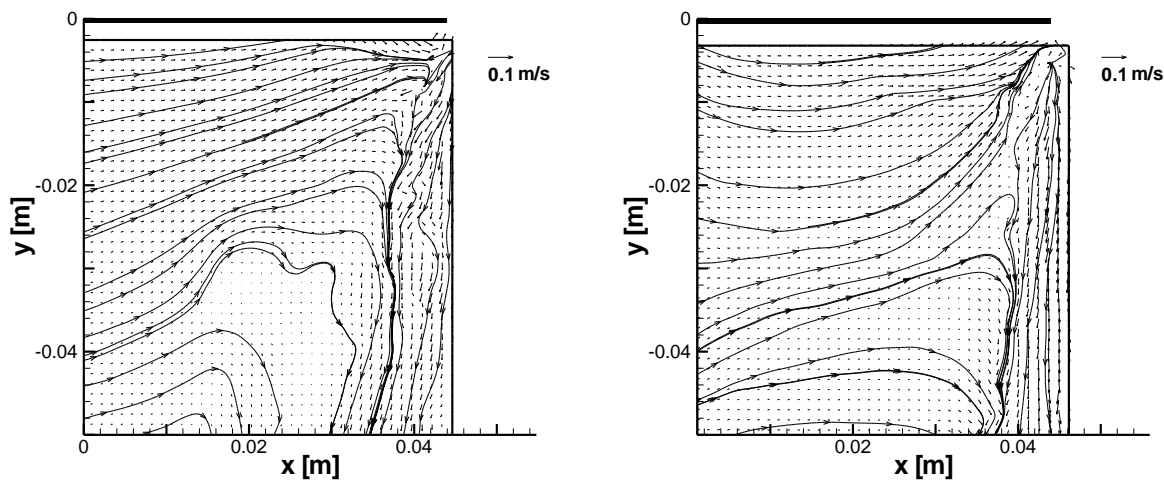

(b)
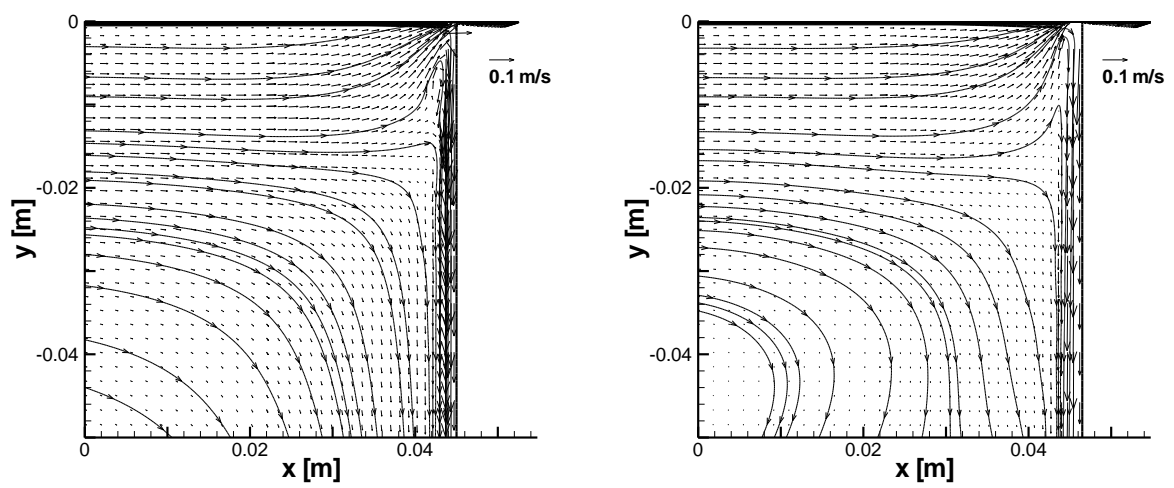

(c)

Fig. 3 Velocity field induced by the steel piezoelectric fan vibrating at $1.5 \mathrm{~mm}$ (peakpeak) amplitude in HFE-7300 with a gap of $1 \mathrm{~mm}$ (left column), and $2.5 \mathrm{~mm}$ (right column). (a) Streaklines constructed from superposition of successive images, (b) streamlines obtained using PIV, and (c) those predicted from the numerical model, respectively are shown in each column. The piezoelectric fan is located at $y=0$, and extends from $\mathrm{x}=0$ (clamped end) to $\mathrm{x}=0.044 \mathrm{~m}$ (vibrating tip). 


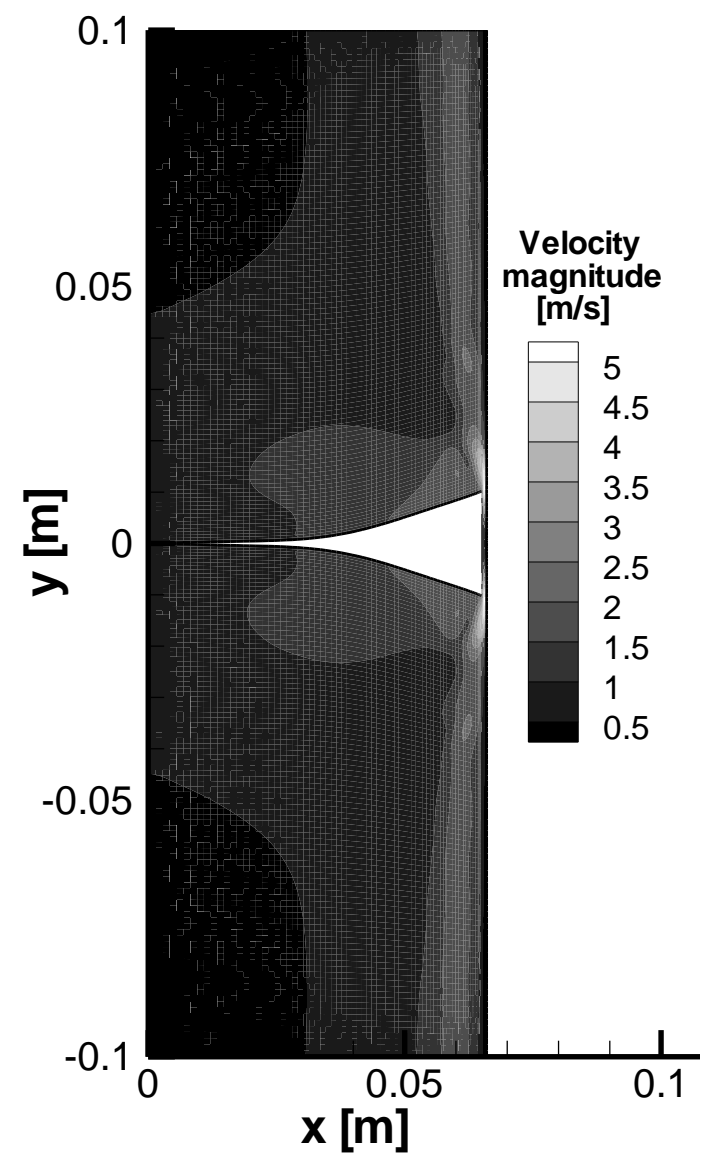

(a)

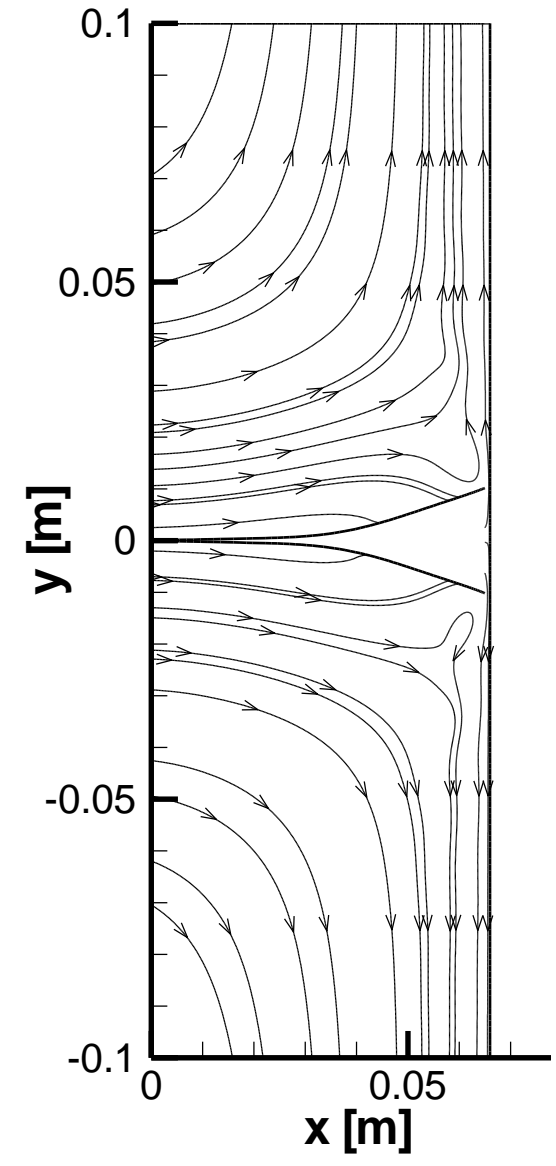

(b)

Fig. 4 Cycle-averaged (a) velocities, and (b) streamlines for $A=10 \mathrm{~mm}$ and $\mathrm{G}=1 \mathrm{~mm}$. 


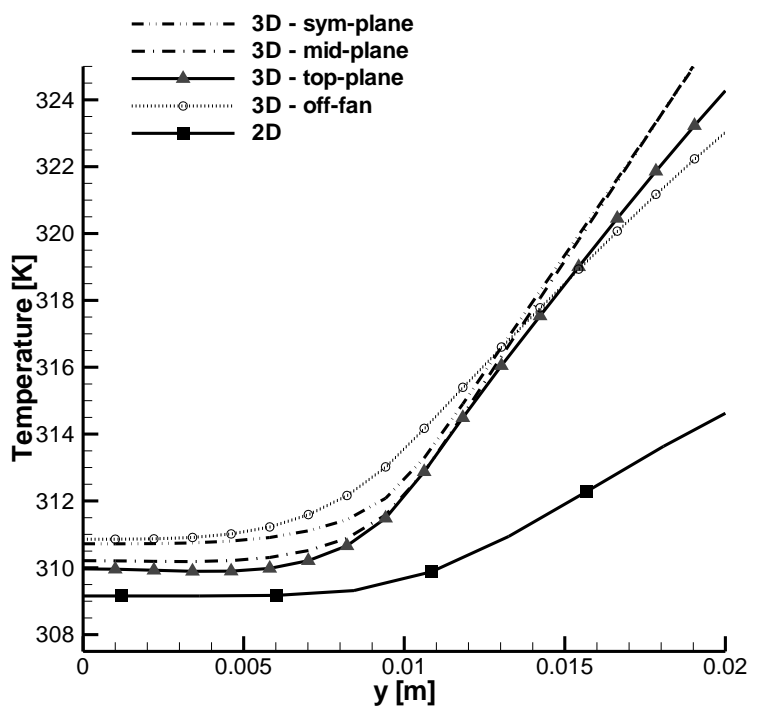

(a)

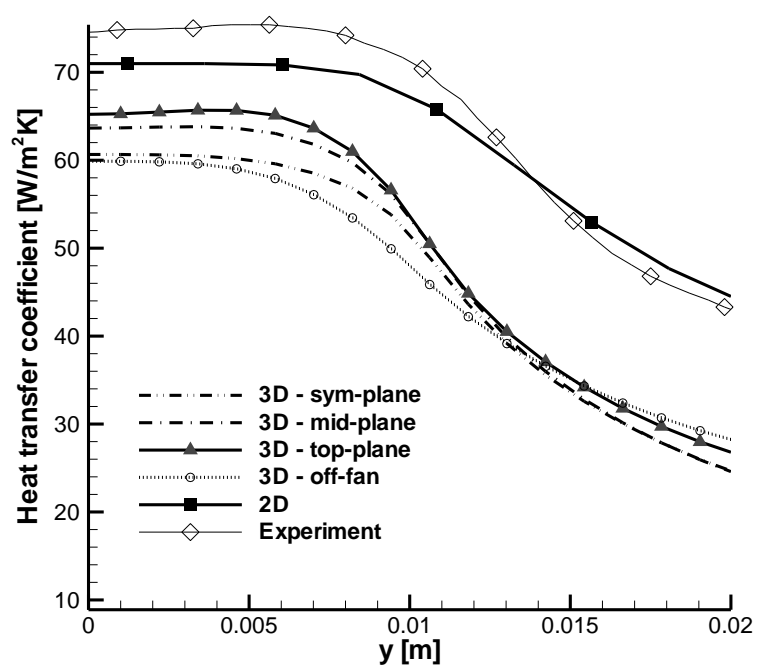

(b)

Fig. 5 Comparison of (a) temperature, and (b) heat transfer coefficient for the 3D model at different heights against the $2 \mathrm{D}$ model results. The experimental heat transfer coefficients for this amplitude of $10 \mathrm{~mm}$ and gap of $1 \mathrm{~mm}$ are also plotted. 


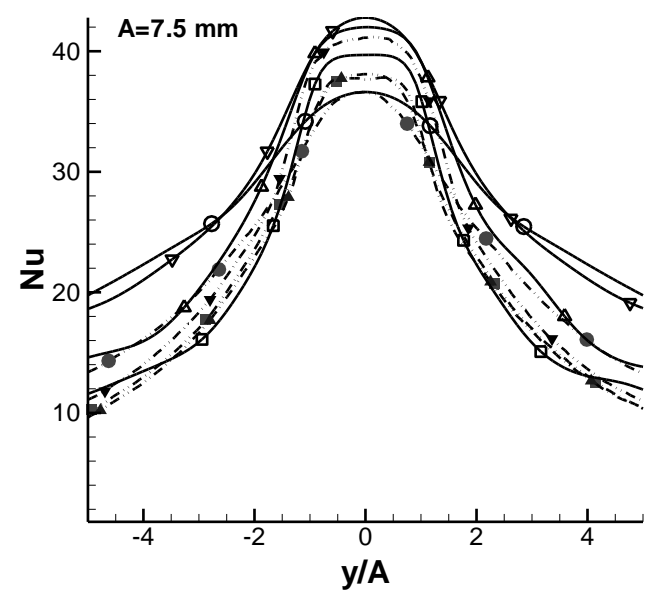

(a)

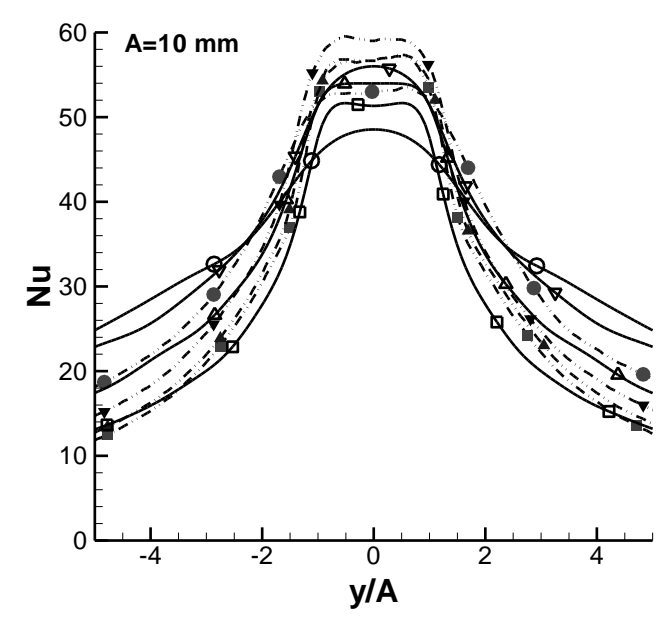

(c)

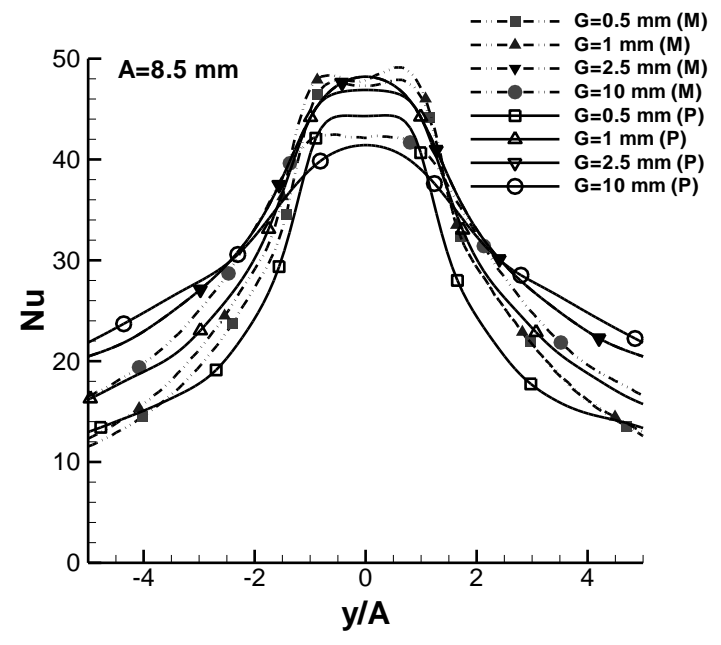

(b)

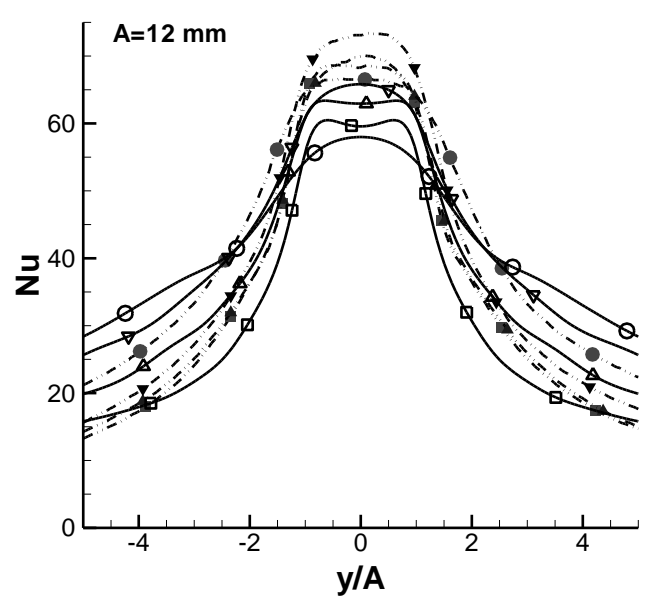

(d)

Fig. 6 Comparison of measured (M) and predicted (P) local Nusselt numbers for different gaps at amplitudes of (a) $7.5 \mathrm{~mm}$, (b) $8.5 \mathrm{~mm}$, (c) $10 \mathrm{~mm}$, and (d) $12 \mathrm{~mm}$. 


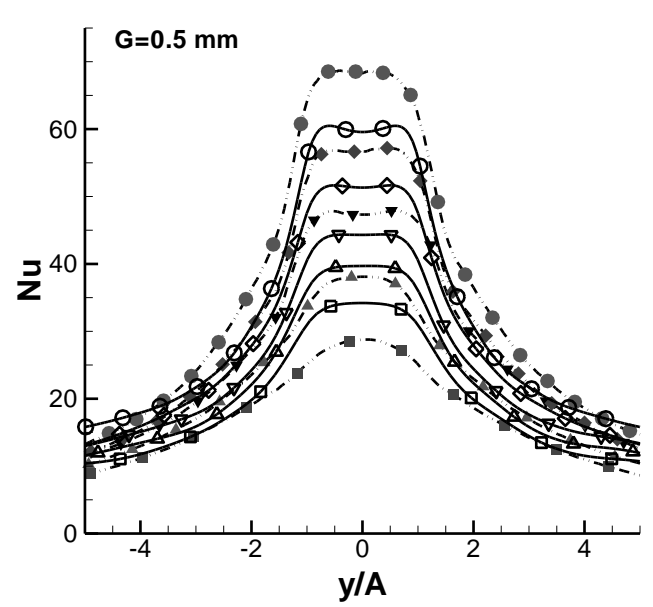

(a)

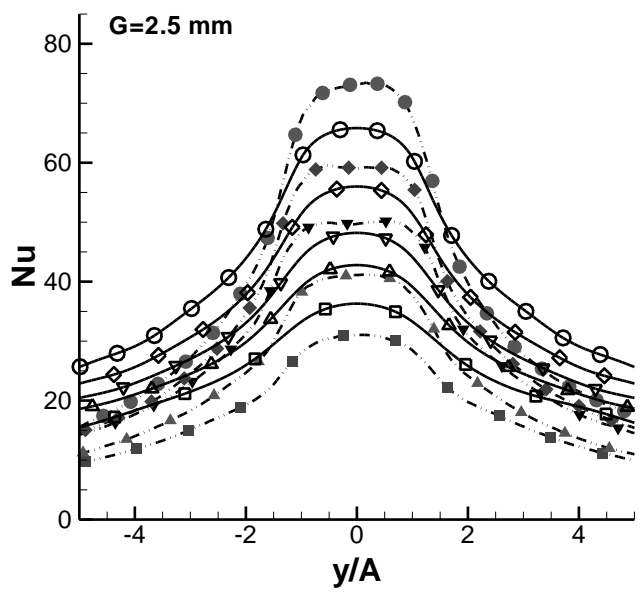

(c)

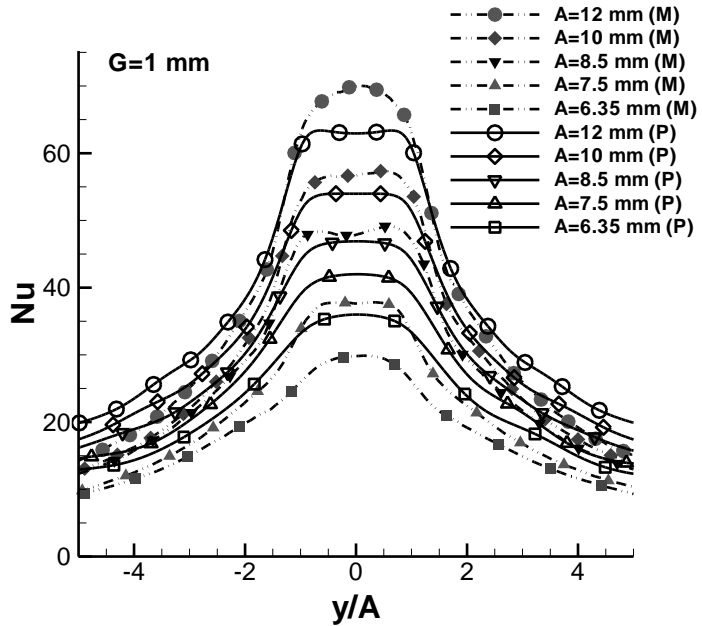

(b)

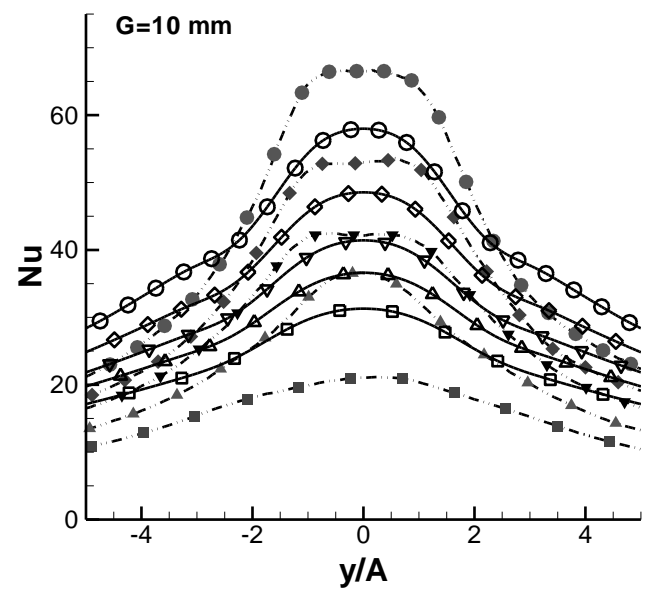

(d)

Fig. 7 Comparison of measured (M) and predicted (P) local Nusselt numbers for different amplitudes at gaps of (a) $0.5 \mathrm{~mm}$, (b) $1 \mathrm{~mm}$, (c) $2.5 \mathrm{~mm}$, and (d) $10 \mathrm{~mm}$. 


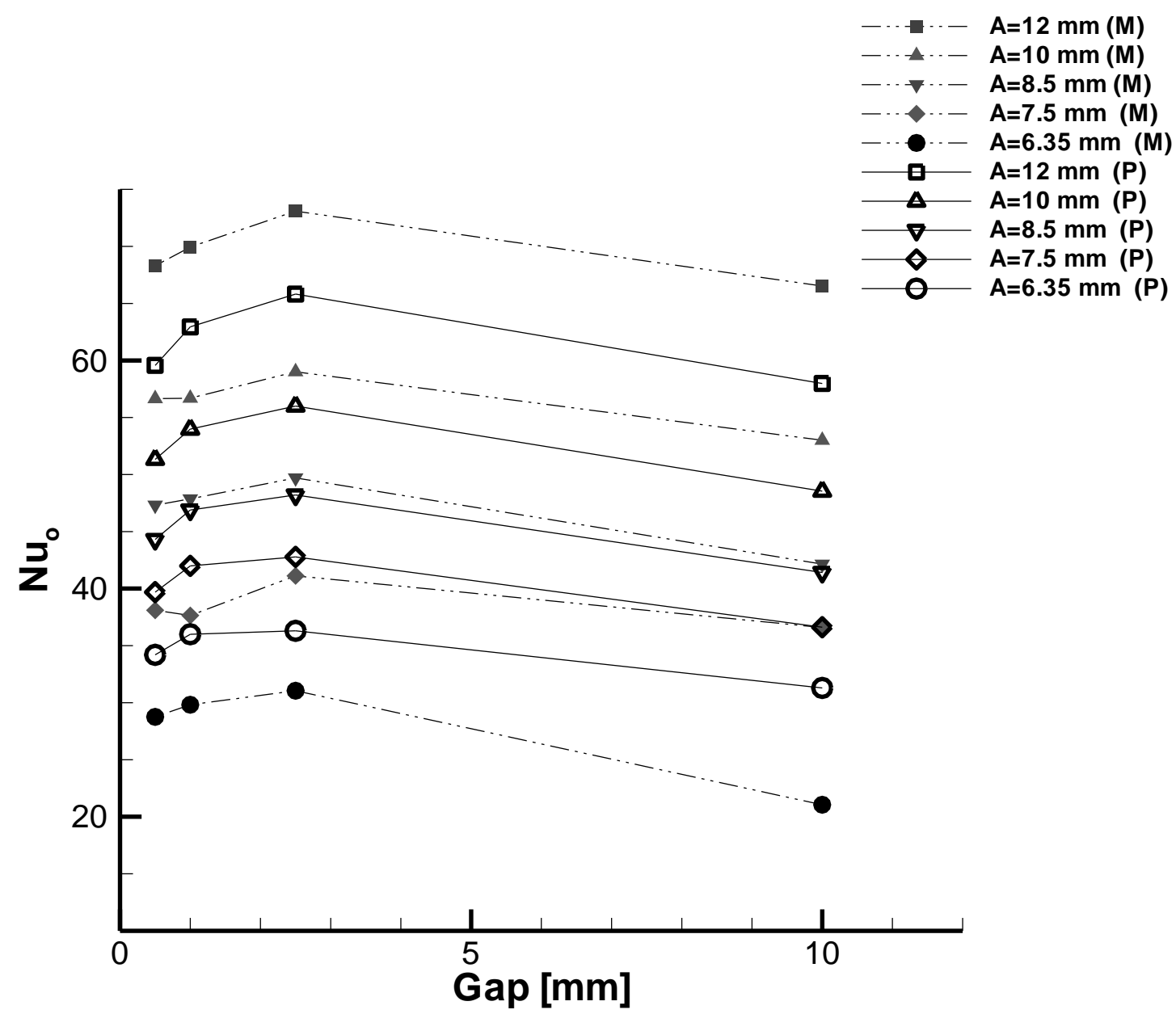

Fig. 8 Comparison of measured (M) and predicted (P) stagnation point Nusselt numbers. 


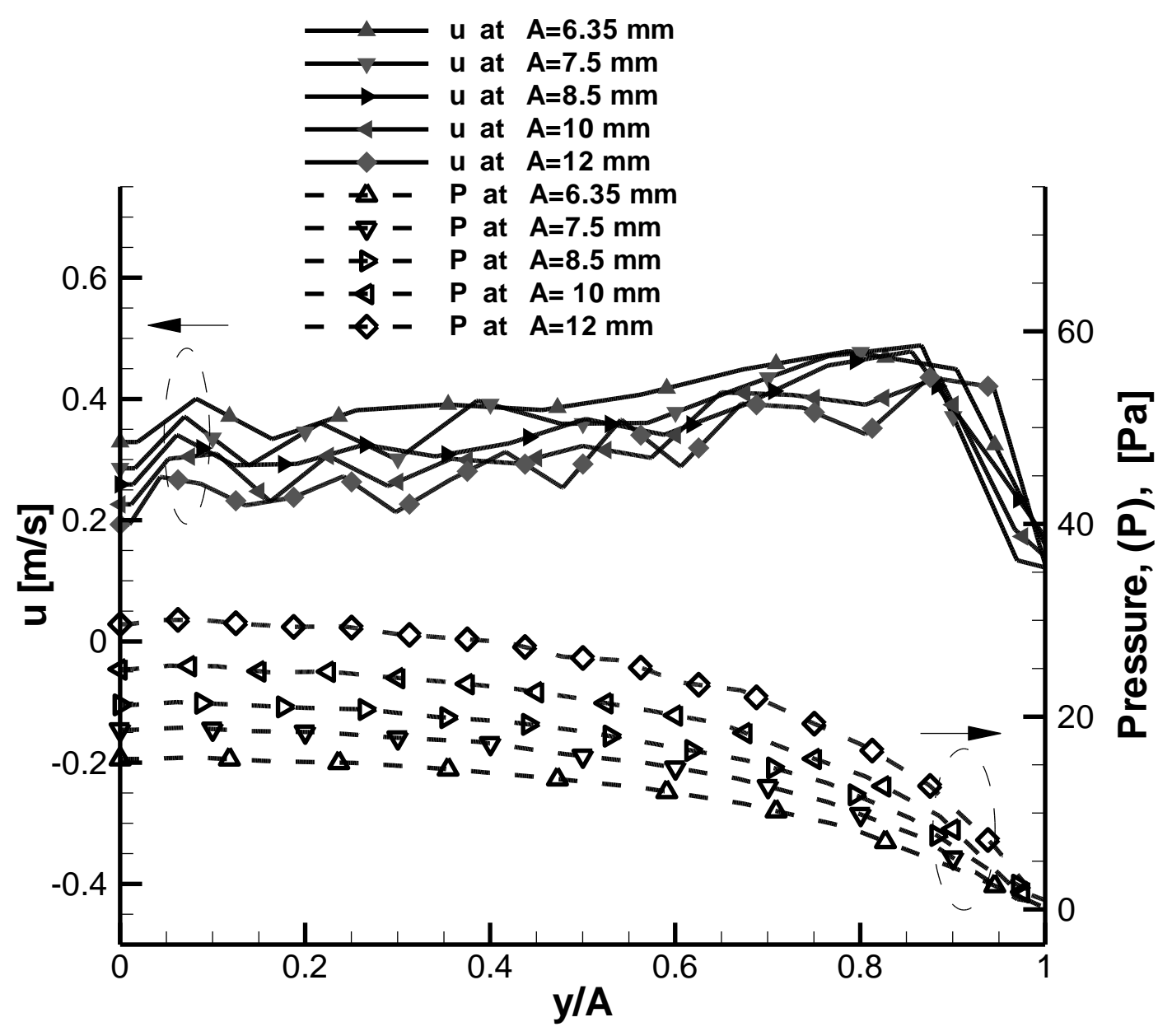

Fig. 9 u-velocity (left y-axis) and pressure (right y-axis) profiles as a function of nondimensional y (y/A) plotted for various amplitudes at $\mathrm{G}=1 \mathrm{~mm}$. 


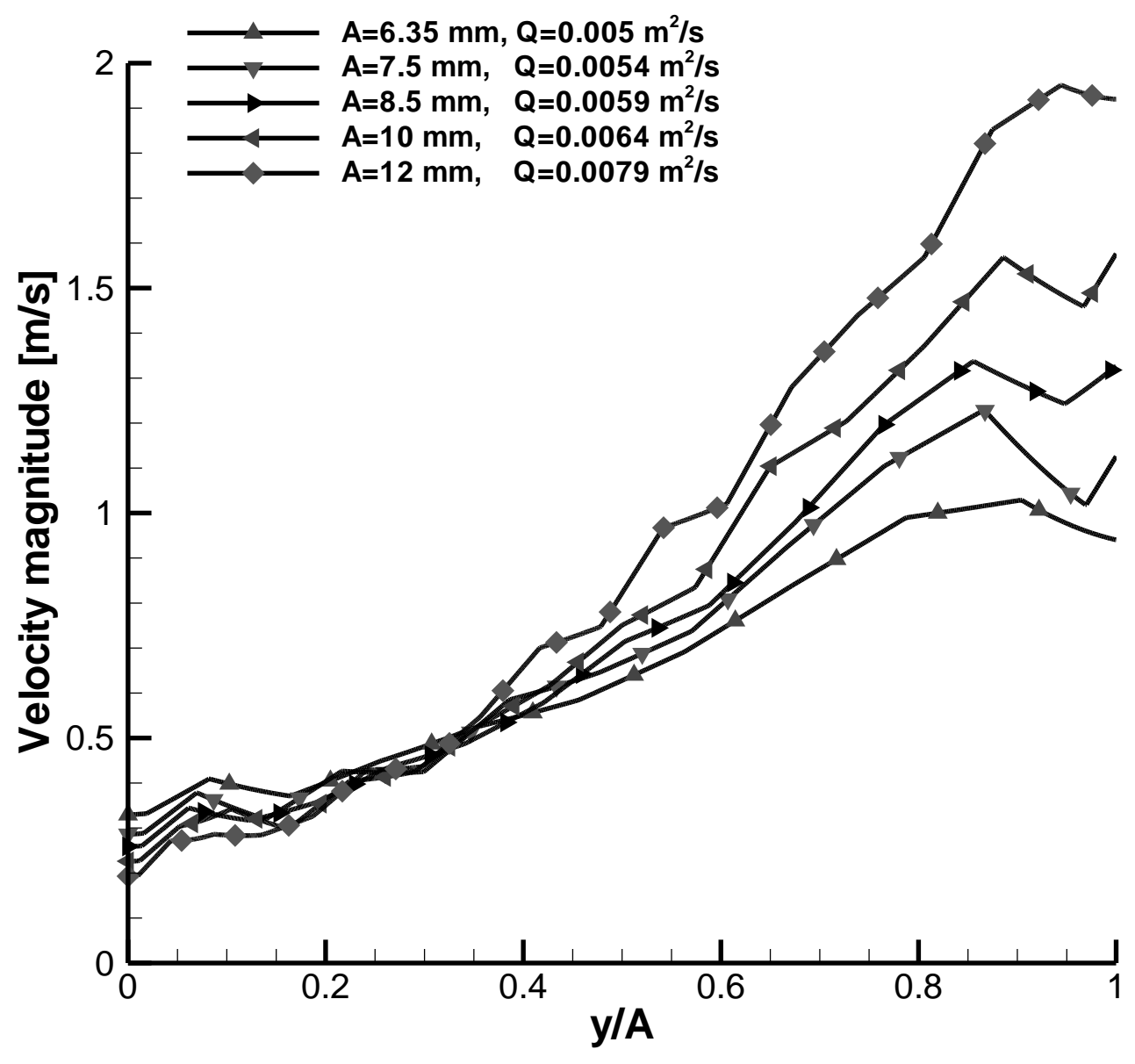

Fig. 10 Velocity magnitude profile for non-dimensional y (y/A) plotted for various amplitudes at $\mathrm{G}=1 \mathrm{~mm}$. 


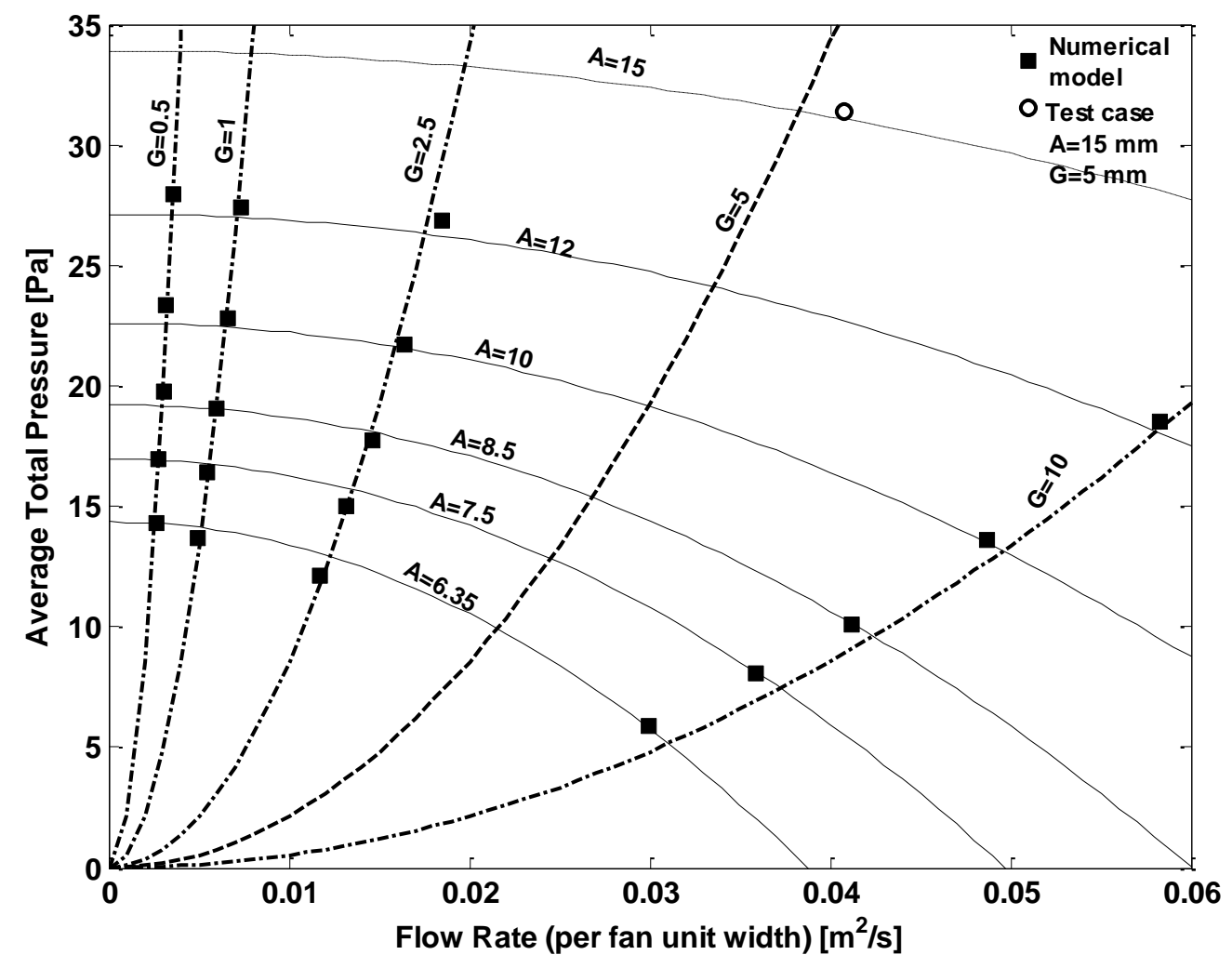

Fig. 11 Development of fan curves for the piezoelectric fan. Amplitude (A) and Gap (G) are in $\mathrm{mm}$. 


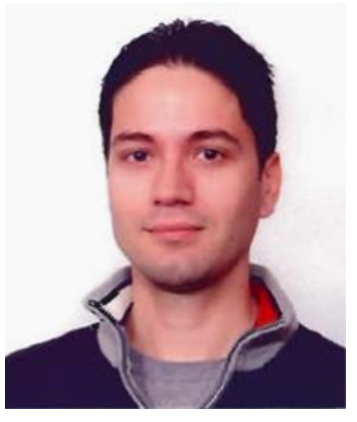

Tolga Açıkalın is a Test R\&D Engineer at Intel Corporation, Chandler, AZ. He received his Ph.D. in 2007 and M.S. in 2003 from Purdue University. He worked on thermal management of electronics using a novel technique, miniature piezoelectric fans, and conducted their fluidic and thermal characterization for his

Ph.D. thesis. He obtained his Bachelor's degree in 2000 from the Middle East Technical University, Turkey. 


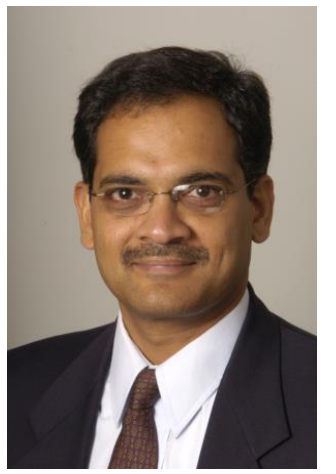

Suresh V. Garimella is the R. Eugene and Susie E. Goodson Professor of Mechanical Engineering at Purdue University. He received his $\mathrm{PhD}$ from the University of California at Berkeley in 1989. He is Director of the NSF Cooling Technologies Research Center, the Electronics Cooling Laboratory and the Solidification Heat Transfer Laboratory. His research interests include thermal microsystems, highperformance compact cooling technologies, electro-thermal co-design and electronics packaging, micro- and nano-scale thermal phenomena, and materials processing. Dr. Garimella has co-authored over 250 refereed journal and conference publications, besides editing or contributing to a number of books. He serves on the Editorial Boards of ASME Journal of Heat Transfer and Experimental Heat Transfer, and has served as Editor of Heat Transfer-Recent Contents and on the Editorial Board of Experimental Thermal and Fluid Science. He is a Fellow of the ASME. His efforts in research and engineering education have been recognized with the 2004 ASME Gustus L. Larson Memorial Award; the 2006 ASME K-16 Clock Award; Graduate School/UWM Foundation Research Award in recognition of Outstanding Research and Creative Activity, 1995; UWM Distinguished Teaching Award in recognition of Demonstrated Dedication to Excellence in Undergraduate Instruction, 1997; and Society of Automotive Engineers' Ralph R. Teetor Educational Award, 1992. 